\title{
$-391 C$ to $G$ substitution in the regulator of G-protein signalling-2 promoter increases susceptibility to the metabolic syndrome in white European men: consistency between molecular and epidemiological studies Kathleen Freson ${ }^{\mathrm{a}, *}$, Katarzyna Stolarz ${ }^{\mathrm{b}, \mathrm{c}, *}$, Raymond Aerts ${ }^{\mathrm{d}}$, Eva Brand ${ }^{\mathrm{e}}$, Stefan-Martin Brand-Herrmann ${ }^{f}$, Kalina Kawecka-Jaszcz ${ }^{d}$, Tatiana Kuznetsova ${ }^{b}$, Valérie Tikhonoff ${ }^{\mathrm{b}, \mathrm{g}}$, Lutgarde Thijs ${ }^{\mathrm{b}}$, Jos Vermylen ${ }^{\mathrm{a}}$, Jan A. Staessen ${ }^{\mathrm{b}}$ and Chris Van Geet ${ }^{\mathrm{a}}$, for the European Project on Genes in Hypertension Investigators
}

Background The regulator of G-protein signalling-2 (RGS2) is a key factor in adipogenesis. We hypothesized that the metabolic syndrome, of which obesity is an important component, might be related to genetic variation in RGS2.

Methods and results We screened the human RGS2 gene. We tested the functionality of a common genetic variant in vitro, ex vivo, and in epidemiological study involving six European populations. The $C$ to $G$ substitution at position -391 in the RGS2 promoter was associated with enhanced RGS2 expression in vitro in transfected 3T3-L1 adipocytes and Chinese hamster cells and ex vivo in adipocytes from male, but not female, volunteers. In 2732 relatives from $\mathbf{5 1 2}$ families and 348 unrelated individuals, randomly recruited from six European populations, the prevalence of GG homozygosity was $\mathbf{5 4 . 1 \%}$. The metabolic syndrome score, a composite of six continuous traits making up this clinical entity, was 0.27 standardized units higher $(P<0.001)$ in 795 GG homozygous men compared with 683 men carrying the $C$ allele. Transmission of the $-391 \mathrm{G}$ allele to male offspring was associated with a 0.20 unit increase in the score $(P=0.039)$. These epidemiological relations were not significant in 1602 women.

Conclusions The $C$ to $G$ substitution at position -391 in the RGS2 promoter increases RGS2 expression in adipocytes and is associated with the metabolic syndrome in white European men. Further experimental and clinical research should establish whether this common polymorphism might be a target for preventive or therapeutic intervention.
J Hypertens 25:117-125 (C) 2007 Lippincott Williams \& Wilkins.

Journal of Hypertension 2007, 25:117-125

Keywords: adipocytes, clinical genetics, epidemiology, metabolic syndrome, molecular biology, syndrome $X$

${ }^{a}$ Center for Molecular and Vascular Biology, University Hospital Gasthuisberg,

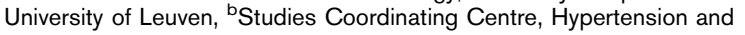
Cardiovascular Rehabilitation Unit, Department of Cardiovascular Diseases, University of Leuven, Belgium, ' First Cardiac Department, Jagiellonian University Medical College, Cracow, Poland, dDivision of Abdominal Surgery, University Hospital Gasthuisberg, University of Leuven, Belgium, ${ }^{e}$ Department of Internal Medicine D, University Clinic Münster, ' Department of Molecular Genetics of Cardiovascular Disease, Leibnitz Institute for Arteriosclerosis Research, University of Münster, Germany and ${ }^{9}$ Department of Clinical and Experimental Medicine, University of Padua, Italy

Correspondence and requests for reprints to Dr Jan A. Staessen, MD, PhD, Studies Coordinating Centre, Laboratory of Hypertension, Hypertension and Cardiovascular Rehabilitation Unit, Department of Cardiovascular Diseases, Campus Gasthuisberg, Herestraat 49, box 702, B-3000 Leuven, Belgium Tel: +32 1634 7104; fax: +32 1634 7106; e-mail: jan.staessen@med.kuleuven.be

Sponsorship: The European Union (IC15-CT98-0329-EPOGH and QLGI-CT2000-01137-EURNETGEN) provided support for the recruitment and phenotyping of families. Research included in the present article was funded by grants (G.0291.98, G.0424.03, G.0453.05 and KAN2000-1523100) from the Fonds voor Wetenschappelijk Onderzoek Vlaanderen (FWO, Brussels, Belgium), by special research grants (Onderzoekstoelage OT/99/28, OT/00/25, OT/05/49 and GOA/2003/09) from the Katholieke Universiteit Leuven (Leuven, Belgium), and by the International Scientific Collaboration between Poland and Flanders (contract numbers BIL 00/18 and BIL 05/22). K.F. is a postdoctoral fellow and C.V.G. is clinical-fundamental researcher of the FWO. K.S. received a scholarship from the Foundation for Polish Science (Poland). E.B. and S.-M.B.-H. received support from the German Ministry of Education and Science (BMBF 0313040C) in the framework of the BioProfile-Project entitled 'Innovations in Treatment Concepts for the Metabolic Syndrome'. Dr Roeder (Rockefeller University, New York, USA), Dr G. Thiel (University of the Saarland Medical Center, Germany) and $\mathrm{Dr}$ G. Suske (Institut fur Molekularbiologie und Tumorforschung, Germany) donated the pCIN4-FLAG-TRAP170, pCMV-Egr1 and pPacUbxSp1 constructs.

Received 14 September 2005 Revised 1 August 2006 Accepted 17 August 2006

the metabolic syndrome, which in prospective studies predicts the development of type 2 diabetes mellitus, hypertension and cardiovascular disease [2].

G-protein signalling plays a key role in adipogenesis $[3,4]$. Regulators of G-protein signalling (RGS) belong to a family of proteins that terminate $G$-protein-mediated 
signal transduction [5,6]. RGS2 is a candidate gene for the metabolic syndrome, because it promotes adipocyte differentiation $[7,8]$ and inhibits pancreatic insulin secretion [9]. Moreover, RGS2 is located on chromosome 1 in a region that is linked to the distribution of body fat in men [10], essential hypertension [11], and the metabolic syndrome [12]. We recently found a common $C$ to $G$ substitution at position -391 in the promoter area of RGS2 and studied its functional relevance in relation to the metabolic syndrome in vitro, ex vivo, and in the participants enrolled in the European Project on Genes in Hypertension (EPOGH) [13].

\section{Methods}

\section{Experimental studies}

From a Belgian population sample [14], we selected 10 women and 10 men who met all criteria for the metabolic syndrome as outlined in the National Cholesterol Education Program - Adult Treatment Panel III [15]. In these individuals and in seven women and seven men without any obvious features of the metabolic syndrome, we screened 1500 base pairs (bp) of the promoter and $4500 \mathrm{bp}$ of the complete region of the RGS2 gene, which comprises five exons and four introns [6]. All primers and polymerase chain reaction (PCR) conditions are available from the authors upon request.

According to previously published methods [16], we studied binding of the RGS2 promoter to nuclear extracts from murine 3T3-L1 adipocytes in the presence or absence of either a competitor or a monospecific antiSp1 antibody (Santa Cruz Biotechnology Inc., Santa Cruz, California, USA). The RGS2 promoter fragment in these in-vitro binding assays spanned nucleotides -405 to -382 . We also studied the RGS2 promoter activity in 3-day differentiated 3T3-L1 adipocytes and Chinese hamster ovary cells [17]. pGL3(RGS2-G) and pGL3(RGS2-C) promoter constructs covered the -527 to +169 region of the gene. For transfection, we mixed the pGL3 constructs with Fugene reagent (Roche Diagnostics, Indianapolis, Indiana, USA). Total cell extracts were prepared after $48 \mathrm{~h}$ of incubation at $37^{\circ} \mathrm{C}$, using an equal volume of lysis buffer (Promega Corporation, Leiden, The Netherlands). To determine the luciferase activity in a luminescence counter (Berthold Technologies, Bad Wildbad, Germany), we mixed $10 \mu$ l cell extract with $50 \mu \mathrm{l}$ luciferase reagent (Promega Corporation). The pPacUbxSp1 [16] and pCMV-Egr1 [18] plasmids were assayed in triplicate in five separate experiments. The pGL3-control vector was the internal control. Luciferase activity was corrected for protein expression. For statistical comparisons, we used Student's $t$-test.

Twelve patients undergoing surgery anonymously donated adipose tissue from the abdominal wall for genotyping and measurement of RGS2 expression. The Ethics Committee of the University of Leuven approved this ex-vivo study. The preparation of cell extracts, the quantification of total protein concentration, the immunoblotting analysis and semiquantitative reverse transcriptase-PCR were carried out as previously described [19]. Blots were revealed with a polyclonal antiRGS2 antibody (Abcam Ltd., Cambridge, UK) or a polyclonal anti-Gq $\alpha$ antibody (SanverTECH, Boechout, Belgium). The secondary antibody was conjugated with horseradish peroxidase. Staining of western blots was performed with an electrochemoluminescence detection reagent (Amersham Biosciences, Uppsala, Sweden). Total RNA was extracted from adipose tissue using TRIzol reagent (Invitrogen, Carlsbad, California, USA). The cDNA content was normalized using primers for $\beta$-actin. The primer sets used to generate specific RGS2 fragments (exons 1-5) consisted of RGS2F(CAGCCG GGGCTCCAGCGGG) and RGS2R(CCATTTCTGG GCTCCCTTTTAC). All PCR reactions (20 cycles) were performed in duplicate on separate adipose tissue RNA samples.

\section{Population studies}

After ethical approval in each country, the EPOGH investigators randomly enrolled nuclear or extended families of white European ethnicity [13]. The overall response rate was $63.7 \%$. They measured clinical and biochemical phenotypes in 4038 participants, who were recruited in Bucharest (Romania, $n=295$ ), Cracow (Poland, $n=326$ ), Hechtel-Eksel (Belgium, $n=2339$ ), Mirano (Italy, $n=355$ ), Novosibirsk (Russian Federation, $n=324$ ), and Pilsen and Prague (Czech Republic, $n=399$ ) [13]. All participants gave informed written consent. We excluded 793 individuals from analysis because one or more components of the metabolic syndrome had not been measured $(n=478)$, because DNA failed to amplify or could not be genotyped $(n=295)$, or because of inconsistency in Mendelian segregation $(n=20)$. To stabilize the correlation matrix in general estimating equations [20], we additionally removed 165 offspring, whose birth order was 4 or higher. The number of EPOGH participants available for analysis was therefore 3080.

The blood pressure phenotype was the average of five consecutive readings obtained at one home visit [13]. The mean arterial pressure was the diastolic blood pressure plus one-third of the difference between systolic and diastolic blood pressures. The body mass index was the weight in kilograms divided by the square of height in meters. The waist-to-hip ratio was the smallest circumference at the waist divided by the largest circumference at the hip. We administered a standardized questionnaire to collect information on each participant's medical history, smoking and drinking habits, and intake of medications [14]. From the type and number of alcoholic beverages used, we calculated the consumption of ethanol in grams per day [14]. We defined regular alcohol 
intake as a daily consumption of at least $5 \mathrm{~g}$. Venous blood samples, collected in the late afternoon (1164 Belgian participants) or after overnight fasting (495 Belgian and 1421 non-Belgian participants), were analysed for serum total and high-density lipoprotein-cholesterol, serum triglycerides, and blood glucose by automated enzymatic methods. In the 495 fasting Belgian participants, we also determined insulin resistance [homeostasis model assessment (HOMA) index [21]] from fasting blood glucose and serum insulin concentrations.

To amplify the RGS2 promoter region with the $C$ to $G$ polymorphism at position -391, we used 5'-CTCTTCA TTCGAAATCAGGC- $3^{\prime}$ as the forward primer and $5^{\prime}$ CATTATCGTTCTCCCGCTG-3' as the reverse primer. Genotyping was performed by a PCR-based restriction method using EagI (New England Biolabs, Beverly, Massachusetts, USA). The $-391 G G$ carriers display two fragments of 186 and $343 \mathrm{bp}$, and the $-391 C G$ carriers have three fragments of 54, 132 and $343 \mathrm{bp}$.

Population means and proportions were compared by Tukey's test for multiple comparisons and the chi-squared statistic with Bonferroni's correction, respectively. Because Shapiro-Wilk's test showed significant departure from normality, we logarithmically transformed the blood glucose and serum triglyceride concentrations. In keeping with the known gender differences in the metabolic syndrome $[2,4,22]$, we analysed women and men separately. After stratification for country and gender, we applied principal component analysis [23] as implemented in the SAS software (version 8.2; SAS Institute Inc., Cary, North Carolina, USA). We summarized six continuous traits - namely, mean arterial pressure, body mass index, waist-to-hip ratio, serum triglycerides, highdensity lipoprotein-cholesterol, and blood glucose - into a single normally distributed metabolic syndrome score. Factor loading (the product-moment correlation [23]) was used to describe the linear association between the metabolic syndrome score and the underlying traits. We searched for possible covariates of the metabolic phenotypes, using stepwise multiple regression analysis with the $P$ value for independent variables to enter and stay in the model set at 0.10 . The variables considered for entry into the models were age, use of $\beta$-blockers, diuretics or angiotensin-converting enzyme inhibitors, intake of lipid-lowering drugs, use of antidiabetic drugs, smok- ing (coded 1 for current smokers or 0 for nonsmokers), and alcohol consumption (coded 1 for individuals reporting a daily intake of at least $5 \mathrm{~g}$ ethanol or coded 0 otherwise), and for women also menopause and use of contraceptive pill. In population-based analyses, we used general estimating equations [20] to test for associations of continuous traits with the RGS2 genotype, while adjusting for covariates as well as for the nonindependence of phenotypes within families. We treated families as clusters and family members as repeated observations within clusters. We defined the working correlation matrix as unstructured. Unrelated individuals were included in the founder generation. To search for heterogeneity between populations, general estimating equation models included appropriate interaction terms with the RGS2 genotype. In family-based analyses, we partitioned the phenotypic variance into within-family and between-family components, using the orthogonal model as implemented in Abecasis' quantitative transmission disequilibrium test (QTDT software, version 2.4, available online: http://www.sph.umich.edu/csg/abecasis/ QTDT) [24].

\section{Results}

\section{Experimental studies}

We found three single-nucleotide polymorphisms in the RGS2 promoter $(-637 \mathrm{~A} / \mathrm{G},-391 \mathrm{C} / \mathrm{G}$, and $-43 \mathrm{~A} / \mathrm{T})$ and four intronic polymorphisms (1058T/A, 1921 deletion TC, 2169 deletion AA, and 2325A/G). All RGS2 single-nucleotide polymorphisms were genotyped in 20 patients with the metabolic syndrome and 14 healthy control individuals (Table 1). The HapMap database (http://www.hapmap.org/cgi-perl/gbrowse/gbrowse/ hapmap) does not contain all markers. Nevertheless, in all populations there was strong linkage disequilibrium across the whole RGS2 gene.

The $-391 \mathrm{C} / \mathrm{G}$ polymorphism (Fig. 1a) is located within a recognition site for transcription factors Sp1 and/or Egr1 (early growth response gene) [6]. The Matinspector software (Genomatix GmbH, Munich, Germany [25]) predicted that the $-391 C$ to $G$ substitution would result in a loss of Sp1, but maintenance of Egr1 recognition. In electrophoretic mobility-shift assays, the $-391 C$ to $G$ substitution led to reduced binding of RGS2 to nuclear extracts prepared from 3T3-L1 adipocytes (Fig. 1b, left). Incubation with a $\mathrm{Sp} 1$ antibody inhibited binding of the

Table 1 Regulator of G-protein signaling-2 genotype analysis

\begin{tabular}{|c|c|c|c|c|c|c|c|c|c|c|c|c|c|c|c|c|c|c|c|c|c|}
\hline & \multicolumn{3}{|c|}{$\begin{array}{c}-637 \text { promoter } \\
\text { rs } 2746071\end{array}$} & \multicolumn{3}{|c|}{$\begin{array}{c}-391 \text { promoter } \\
\text { rs } 2746072\end{array}$} & \multicolumn{3}{|c|}{$\begin{array}{l}\text {-43 promoter } \\
\text { rs12130717 }\end{array}$} & \multicolumn{3}{|c|}{$\begin{array}{l}1058 \text { intron } \\
\text { rs } 2746073\end{array}$} & \multicolumn{3}{|c|}{$\begin{array}{l}1921 \text { intron } \\
\text { rs5779653 }\end{array}$} & \multicolumn{3}{|c|}{$\begin{array}{l}2169 \text { intron } \\
\text { rs10598428 }\end{array}$} & \multicolumn{3}{|c|}{$\begin{array}{l}2325 \text { intron } \\
\text { rs17647363 }\end{array}$} \\
\hline & $\mathrm{A} / \mathrm{A}$ & $A / G$ & $\mathrm{G} / \mathrm{G}$ & $\mathrm{G} / \mathrm{G}$ & $\mathrm{G} / \mathrm{C}$ & $\mathrm{C} / \mathrm{C}$ & $\mathrm{A} / \mathrm{A}$ & $\mathrm{A} / \mathrm{T}$ & $\mathrm{T} / \mathrm{T}$ & $\mathrm{T} / \mathrm{T}$ & T/A & $\mathrm{A} / \mathrm{A}$ & $\mathrm{N} / \mathrm{N}$ & $\Delta \mathrm{TC} / \mathrm{N}$ & $\Delta \mathrm{TC} / \Delta$ & $\mathrm{N} / \mathrm{N}$ & $\Delta \mathrm{AA} / \mathrm{N}$ & $\Delta \mathrm{AA} / \Delta$ & $\mathrm{A} / \mathrm{A}$ & $\mathrm{A} / \mathrm{G}$ & $\mathrm{G} / \mathrm{G}$ \\
\hline $\begin{array}{l}\text { Metabolic syndrome } \\
\quad(n=20)\end{array}$ & 87.5 & 0 & 12.5 & 93.8 & 0 & 6.2 & 87.5 & 0 & 12.5 & 87.5 & 0 & 12.5 & 93.8 & 0 & 6.2 & 93.8 & 0 & 6.2 & 87.5 & 0 & 12.5 \\
\hline Controls $(n=14)$ & 64.2 & 35.8 & 0 & 35.8 & 50.0 & 14.2 & 64.2 & 35.8 & 0 & 28.5 & 21.5 & 50.0 & 35.8 & 50.0 & 14.2 & 35.8 & 50.0 & 14.2 & 64.2 & 35.8 & 0 \\
\hline
\end{tabular}

Single-nucleotide polymorphisms are indicated by their position in the regulator of G-protein signaling-2 gene and by the National Centre for Biotechnology Information reference number. $\Delta$ indicates a deletion. Values are genotype frequencies in per cent. 
Fig. 1

(a)

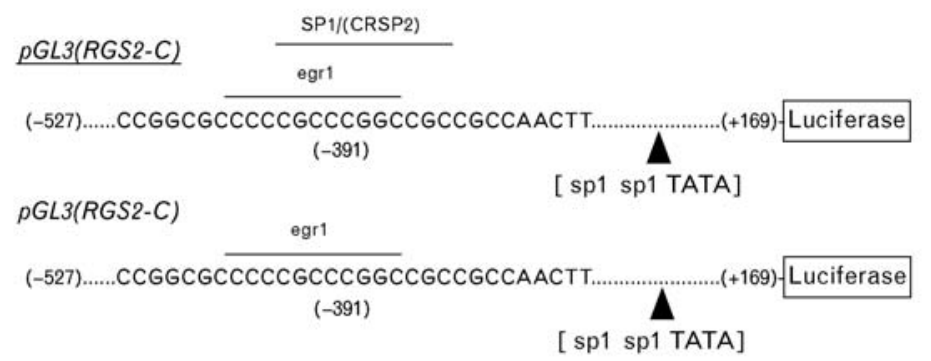

In-vitro experiments in 3T3-L1 adipocytes

(b)

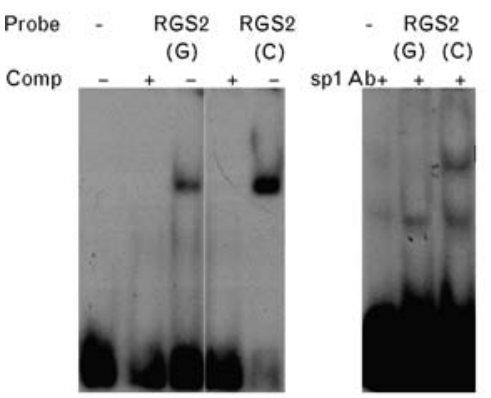

Ex-vivo experiments in human adipocytes (c)

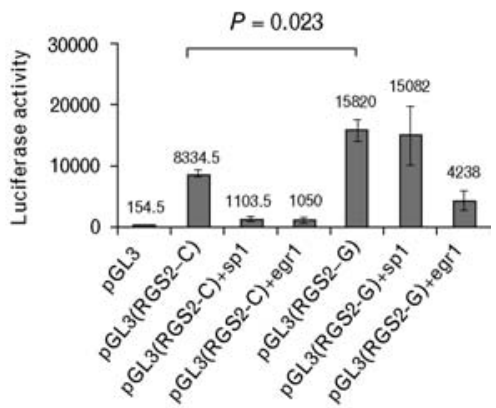

(d)
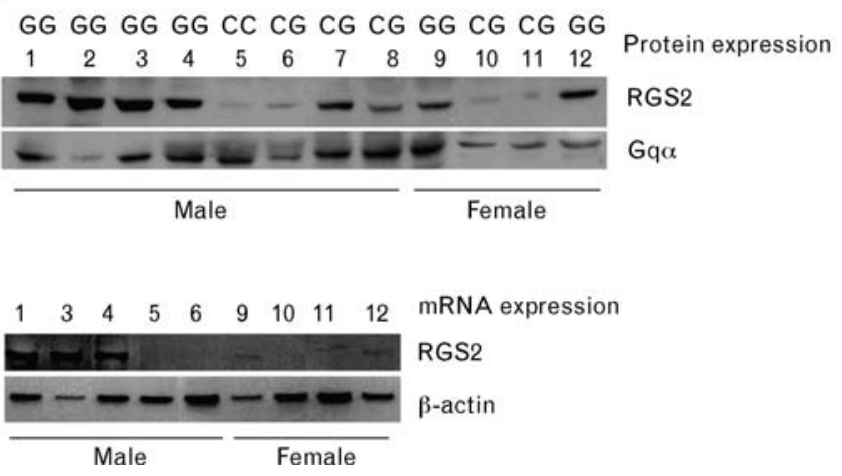

Polymorphic site in the $5^{\prime}$ region of the regulator of G-protein signaling-2 (RGS2) gene, binding to nuclear extracts, and effects on RGS2 expression. (a) RGS2 promoter-luciferase constructs with either the $G$ or $C$ allele. The transcription factors Sp1 and Egr1 and the TATA recognition site regulating RGS2 expression are represented. CRSP2 indicates the X-linked cofactor required for Sp1 transcriptional activation, subunit 2. (b) Binding of RGS2(G) or RGS2(C) fragments to nuclear extracts from 3T3-L1 adipocytes in the presence or absence of a competitor (Comp, left) or a Sp1 antibody (sp1 Ab, right). Data represent three experiments. (c) Transactivation studies with RGS2 promoter constructs in 3T3-L1 adipocytes. The empty pGL3 vector was the negative control. Cotransfection studies were performed in the presence of the pCMV-Egr1 or pPacUbxSp1 plasmids. Bars represent the mean \pm SD of five experiments. (d) Expression of RGS2 and Gq $\alpha$ (control) protein and RGS2 and $\beta$-actin (control) mRNA in adipose tissue from female and male donors. The RGS2 genotype and the number of patients are given.

RGS2 promoter fragment containing the $C$ allele (Fig. 1b, right). In transfected 3T3-L1 adipocytes (Fig. 1c) and Chinese hamster ovary cells (data not shown), the RGS2 $G$-allele promoter fragment increased transcription in comparison with the $C$ allele.

In immunoblots (Fig. 1d, top) and in semiquantitative reverse transcriptase-PCR experiments (Fig. 1d, bottom), adipocytes of $G G$ homozygous men showed higher RGS2 levels in terms of protein and mRNA content than those collected from men carrying the $C$ allele or those from women irrespective of their RGS2 genotype.

\section{Epidemiological studies}

The study population consisted of 2732 relatives from 512 families and 348 unrelated individuals with significant differences between countries in age, waist-to-hip ratio, blood pressure, smoking and drinking habits, use of 
Table 2 Characteristics of the study participants by country

\begin{tabular}{|c|c|c|c|c|c|c|}
\hline Characteristic & $\begin{array}{l}\text { Belgium } \\
(n=1659)\end{array}$ & $\begin{array}{l}\text { Czech Republic } \\
\quad(n=293)\end{array}$ & $\begin{array}{c}\text { Italy } \\
(n=312)\end{array}$ & $\begin{array}{l}\text { Poland } \\
(n=317)\end{array}$ & $\begin{array}{l}\text { Romania } \\
(n=203)\end{array}$ & $\begin{array}{c}\text { Russia } \\
(n=296)\end{array}$ \\
\hline \multicolumn{7}{|l|}{ Clinical features } \\
\hline Female sex (\%) & 51.0 & 48.5 & 53.5 & 54.9 & 54.2 & 55.1 \\
\hline Age (years) & $43.7 \pm 17.6$ & $37.6 \pm 13.9$ & $42.0 \pm 14.1$ & $35.6 \pm 13.9$ & $38.2 \pm 15.4$ & $38.2 \pm 14.0$ \\
\hline Body mass index $\left(\mathrm{kg} / \mathrm{m}^{2}\right)^{\mathrm{a}}$ & $25.0 \pm 4.4$ & $25.8 \pm 4.5$ & $25.5 \pm 4.4$ & $25.5 \pm 4.9$ & $24.9 \pm 5.3$ & $25.3 \pm 5.0$ \\
\hline Waist-to-hip ratio ${ }^{\mathrm{b}}$ & $0.83 \pm 0.09$ & $0.83 \pm 0.09$ & $0.85 \pm 0.09$ & $0.84 \pm 0.09$ & $0.83 \pm 0.09$ & $0.81 \pm 0.08$ \\
\hline Systolic blood pressure $(\mathrm{mmHg})^{\mathrm{C}}$ & $122.5 \pm 15.6$ & $121.8 \pm 15.5$ & $125.0 \pm 15.4$ & $126.6 \pm 17.6$ & $122.9 \pm 19.6$ & $125.5 \pm 19.0$ \\
\hline Diastolic blood pressure $(\mathrm{mmHg})^{\mathrm{c}}$ & $75.2 \pm 10.9$ & $76.4 \pm 11.0$ & $79.6 \pm 9.6$ & $79.1 \pm 11.6$ & $78.9 \pm 13.1$ & $80.6 \pm 12.1$ \\
\hline \multicolumn{7}{|l|}{ Lifestyle } \\
\hline Smokers (\%) & 20.7 & 21.8 & 23.1 & 27.4 & 23.2 & 29.7 \\
\hline Alcohol intake $\geq 5 \mathrm{~g} /$ day $(\%)$ & 18.4 & 41.6 & 42.0 & 18.6 & 27.1 & 47.6 \\
\hline \multicolumn{7}{|l|}{ Use of drugs } \\
\hline Antihypertensive agents (\%) & 14.3 & 17.4 & 15.1 & 19.6 & 16.3 & 13.9 \\
\hline Diuretics (\%) & 6.2 & 6.1 & 8.0 & 7.3 & 5.4 & 7.4 \\
\hline$\beta$-Blockers (\%) & 8.3 & 12.0 & 4.2 & 11.4 & 5.4 & 1.7 \\
\hline Lipid-lowering agents (\%) & 4.0 & 3.4 & 2.6 & 1.0 & 0.5 & 0.0 \\
\hline Antidiabetic agents (\%) & 0.7 & 2.1 & 2.0 & 1.3 & 1.0 & 1.0 \\
\hline \multicolumn{7}{|l|}{ Biochemical measurements } \\
\hline Serum total cholesterol $(\mathrm{mmol} / \mathrm{l})$ & $5.29 \pm 1.09$ & $5.20 \pm 1.13$ & $5.24 \pm 1.14$ & $5.00 \pm 1.13$ & $4.85 \pm 1.28$ & $4.98 \pm 1.23$ \\
\hline Serum HDL-cholesterol $(\mathrm{mmol} / \mathrm{l})$ & $1.40 \pm 0.40$ & $1.44 \pm 0.33$ & $1.22 \pm 0.29$ & $1.57 \pm 0.38$ & $0.96 \pm 0.25$ & $0.98 \pm 0.32$ \\
\hline Serum triglycerides $(\mathrm{mmol} / \mathrm{l})$ & $2.24(2.19-2.29)$ & $1.22(1.14-1.31)$ & $0.97(0.92-1.03)$ & $1.09(1.02-1.16)$ & $1.45(1.44-1.46)$ & $1.35(1.27-1.43)$ \\
\hline Blood glucose $(\mathrm{mmol} / \mathrm{l})$ & $4.90(4.84-4.95)$ & $5.25(5.13-5.37)$ & $5.01(4.92-5.11)$ & $4.47(4.37-4.57)$ & $4.90(4.78-5.02)$ & $4.79(4.71-4.86)$ \\
\hline
\end{tabular}

Data presented as the mean \pm SD or, in cases of skewed distributions, values are the geometric means (95\% confidence interval). Differences between countries were significant $(P \leq 0.05)$ except for female sex, body mass index, and use of diuretics and antidiabetic drugs. To convert values for total and high-density lipoprotein $(\mathrm{HDL})$ cholesterol to milligrams per decilitre, divide by 0.02586 . To convert values for triglycerides to milligrams per decilitre, divide by 0.01129 . To convert values for glucose to milligrams per decilitre, divide by 0.05551 . ${ }^{a}$ The body mass index is weight in kilograms divided by the square of the height in meters. ${ }^{\mathrm{b}}$ The waist-to-hip ratio is the smallest circumference at the waist divided by the largest circumference at the hip level. ${ }^{\mathrm{c}}$ Average of five blood pressure readings obtained at one home visit.

medications, and serum lipids, but not in sex distribution and body mass index (Table 2). Among women, 1097 were premenopausal (256 on oral contraceptives) and 505 were menopausal (37 on hormonal replacement therapy).

The principal component analysis revealed remarkable consistency in the summary score for the metabolic syndrome across the six countries and among women and men. Indeed, eigenvalues among these 12 strata ranged from 2.37 to 2.96 and from 0.92 to 1.16 for the first and second principal components, respectively. The first principal component (Fig. 2a), but not the second (data not shown), consistently showed high loadings on the six constituents of the metabolic syndrome. In women and men, the first principal component on average accounted for 45.1 and $43.4 \%$ of the overall variance in the six contributing phenotypes, respectively. We therefore used the first principal component as a standardized and normally distributed summary score (mean, 0 ; standard deviation, 1) for the metabolic syndrome.

In stepwise multiple regression, the metabolic syndrome score increased with age (Fig. 2b), use of $\beta$-blockers and diuretics, and in men also with alcohol consumption. In addition, in women, the metabolic syndrome score was independently and positively associated with menopause and decreased with the intake of lipid-lowering drugs, but was not significantly associated with the use of oral contraceptives or alcohol consumption. In a subsample of 495 fasting Belgian participants, we noticed a strong positive correlation $(P<0.0001)$ between the metabolic syndrome score and the HOMA index [21]. Per unit variation in the HOMA index, the metabolic syndrome score changed ( \pm SE) by $2.82 \pm 0.31 \mathrm{U}$ in 253 women and by $2.12 \pm 0.32 \mathrm{U}$ in $242 \mathrm{men}$.

The within-country frequencies of the genotypes complied with Hardy-Weinberg equilibrium $(0.13<$ $P<0.85$ ). The overall prevalence was $54.1 \%$ for $G G$, $39.5 \%$ for $C G$, and $6.4 \%$ for $C G$. Because across countries the frequency of $C G$ homozygosity ranged only from 4.1 to $8.4 \%$, we contrasted $G G$ homozygotes with $C$ allele carriers. Among women $(0.09<P<0.99)$ and men $(0.10<P<0.97)$, we did not detect any heterogeneity between countries in the relations of the metabolic syndrome score or any of the six contributing phenotypes with the RGS2 genotype. In men, with adjustments applied as described before and irrespective of generation, $G G$ homozygosity was associated with a worse metabolic syndrome score (Table 3). Sensitivity analyses demonstrated that this association was consistently significant in Eastern and Western European countries, in nonfasting participants ( $70.2 \%$ of the Belgian sample) and fasting participants (29.8 of the Belgian participants and all individuals from other countries), and in unmedicated individuals and those taking antihypertensive, antidiabetic or lipid-lowering drugs. In men, from six components of the metabolic syndrome score, only triglycerides were significantly higher in $G$ allele carriers than $C G$ homozygotes (Table 4).

Among 520 informative male offspring, transmission of the $G$ allele was associated with an increase in the metabolic syndrome score by 0.27 standardized units $\left(\chi^{2}=4.27, P=0.039\right)$. In women, neither the populationbased analyses (Tables 3 and 4 ) nor the family-based 
Fig. 2

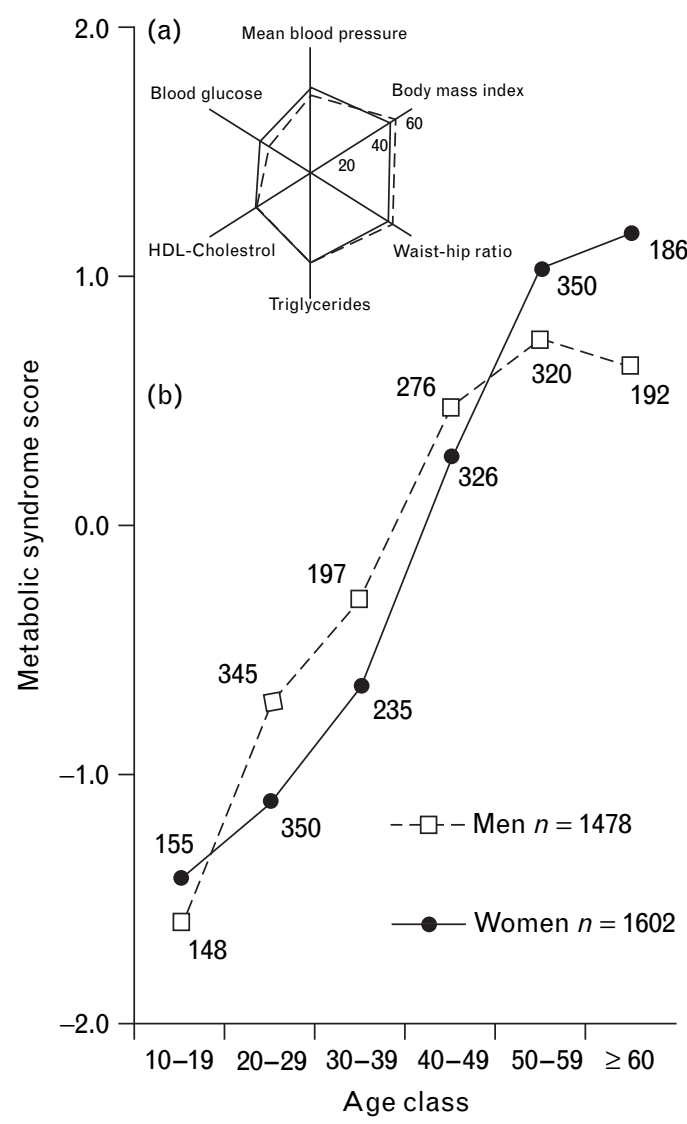

Metabolic syndrome score by gender and age. (a) The metabolic syndrome score was the first principal component derived from six continuous traits. The hexagons represent the loading factors on six contributing traits in men (full line) and women (dotted line). Loading factors were weighted means across six countries and were positive except for high-density lipoprotein (HDL)-cholesterol. (b) Values are unadjusted means of the metabolic syndrome score in men and women. The number of individuals contributing to each mean is presented.

approach revealed significant association between the metabolic syndrome score adjusted for covariates and the RGS2 polymorphism. Among 540 informative female offspring, the parameter estimate associated with transmission of the $G$ allele was +0.068 unit $\left(\chi^{2}=0.53\right.$, $P=0.47)$. When we redefined the metabolic syndrome score according to National Cholesterol Education Program - Adult Treatment Panel III criteria [15], the relative risk associated with the $G G$ genotype was 1.43 (95\% confidence interval, $1.02-1.75 ; P=0.043$ ) in men and 0.97 (95\% confidence interval, -0.35 to 1.25 ; $P=0.85)$ in women.

\section{Discussion}

We identified a common $C$ to $G$ substitution at position -391 in the RGS2 promoter. In-vitro experiments demonstrated that this single-nucleotide polymorphism had functional implications, with the $G$ allele being associated with the highest promoter activity. Our trans- fection experiments suggested that $\mathrm{Sp} 1$ acts as transcriptional repressor on the $G$-allele promoter, but further studies are needed to support this hypothesis. Other investigators demonstrated that $\mathrm{Sp} 1$ can directly repress the CCAAT enhancer-binding protein- $\alpha$ during adipogenesis [26]. In ex-vivo experiments, adipocytes from $G G$ homozygous men showed higher RGS2 levels than those collected from male $C$-allele carriers or from women irrespective of their genotype. Among white Europeans, the prevalence of $G G$ homozygosity was $54.1 \%$. The metabolic syndrome score, which was a composite of six continuous traits, was significantly higher in male $G G$ homozygotes than in their $G$-allele counterparts. Transmission of the $-391 G$ allele to male offspring was also associated with a higher metabolic syndrome score.

Dichotomization of continuously distributed phenotypes requires the definition of arbitrary thresholds and removes part of the phenotypic variance. Furthermore, current definitions of the metabolic syndrome, all of which involve categorical measurements, are not uniform - so estimates of prevalence differ as a mere consequence of the applied criteria. There is increasing recognition that for complex traits, such as the metabolic syndrome, quantitative phenotypes are more informative than diagnostic categories [24]. For these reasons, we defined the continuously distributed metabolic syndrome score, which had high loadings on each of the six contributing traits. Other investigators choose a similar approach [27]. The metabolic syndrome score, as derived in our study, closely correlated with the HOMA index [21], and this association was of similar magnitude in women and men. Clustering of the traits making up the metabolic syndrome may be due to pleiotropy, when the same gene(s) influences several traits, or to common environmental determinants. The San Antonio Heart Study [28] noticed significant genetic correlations of insulin with body mass index, high-density lipoprotein-cholesterol, and triglycerides and therefore provided evidence for pleiotropy. Among the twins enrolled in Swedish Adoption/Twin Study [29], a common genetic factor contributed to the variability in body mass index, insulin resistance, serum triglycerides and systolic blood pressure, and accounted for over 50, 40, 11 and $6 \%$ of the variances, respectively.

Among the RGS family, RGS2 was originally identified as an early response gene that was upregulated in activated $\mathrm{T}$ cells [6]. Initially named G0S8, the gene was renamed after sequence comparisons clarified that it contained the highly conserved 120-amino-acid core domain of RGS proteins. In vitro, RGS2 interacts with $\mathrm{G} \alpha_{\mathrm{q} / 11}$ and stimulates GTP-ase activity [30]. RGS proteins not only downregulate the agonist-induced $G$-protein-mediated signal transduction at the plasma membrane, but also translocate from the cytoplasm to the nucleus, where they 
Table 3 Metabolic syndrome score by regulator of G-protein signaling-2 genotype, gender and generation

\begin{tabular}{|c|c|c|c|c|c|c|}
\hline & \multirow{2}{*}{$\begin{array}{c}\text { GG homozygotes } \\
\text { Number }\end{array}$} & \multicolumn{2}{|c|}{$C$ allele carriers } & \multicolumn{2}{|c|}{ Phenotypic differences $^{a}$} & \multirow[b]{2}{*}{$P$} \\
\hline & & Mean $\pm \mathrm{SD}^{\mathrm{b}}$ & Number & Mean $\pm \mathrm{SD}^{\mathrm{b}}$ & Mean (95\% confidence interval) & \\
\hline Men & 795 & $+0.122 \pm 0.050$ & 683 & $-0.148 \pm 0.050$ & $+0.270(+0.135$ to +0.405$)$ & $<0.001$ \\
\hline Fathers & 373 & $+0.874 \pm 0.072$ & 348 & $+0.580 \pm 0.075$ & $+0.294(+0.090$ to +0.498$)$ & 0.005 \\
\hline Sons & 422 & $-0.592 \pm 0.061$ & 335 & $-0.814 \pm 0.068$ & $+0.222(+0.046$ to +0.398$)$ & 0.014 \\
\hline Women & 872 & $-0.006 \pm 0.046$ & 730 & $+0.008 \pm 0.049$ & $-0.015(-0.142$ to +0.011$)$ & 0.82 \\
\hline Mothers & 440 & $+0.817 \pm 0.065$ & 371 & $+0.880 \pm 0.071$ & $-0.063(-0.253$ to +0.127$)$ & 0.52 \\
\hline Daughters & 432 & $+0.827 \pm 0.058$ & 359 & $-0.900 \pm 0.056$ & $+0.073(-0.081$ to +0.227$)$ & 0.35 \\
\hline
\end{tabular}

${ }^{a}$ The phenotypic difference was computed by subtracting the value in $C$ allele carriers from that in GG homozygotes. ${ }^{\mathrm{b}}$ The metabolic syndrome score was derived by principal component analysis from six continuous traits and is expressed in standardized units. Statistical parameters, which were obtained by generalized estimating equations [20], were adjusted for age (linear and squared terms), treatment with diuretics, $\beta$-blockers and lipid-lowering drugs, smoking and alcohol intake, and in women also for use of the contraceptive pill and menopause. In the generalized estimating equation analyses, families were treated as clusters and family members as repeated observations within clusters. The working correlation matrix was unstructured. Unrelated individuals were included in the founder generation.

influence transcription and participate in the control of the cell cycle $[7,31,32]$.

Several lines of evidence suggest that RGS2 is a candidate gene for the metabolic syndrome via regulation of G-protein-mediated signalling as well as transcription. RGS2 expression is enhanced at the beginning of the differentiation of adipocytes $[7,8]$. Transfection of $\beta$ TC3 pancreatic islet cells with RGS2 completely abolished the effect of insulinotropic peptide on insulin release, whereas the glucose-stimulated insulin secretion remained well preserved [9]. In 3T3-L1 adipocytes, endogenous $\mathrm{Gq}$ function is necessary for insulin-induced insulin-responsive glucose transporter (GLUT4) translocation [33]. Microinjection of RGS2 protein, which inhibits Gq, blocked insulin-mediated GLUT4 translocation [33]. RGS2 overexpression stimulated the adipogenesis of a fibroblastic cell line, but only in the presence of a ligand for the peroxisome proliferator-activated receptor gamma (PPAR $\gamma$ ) [8]. These experiments demonstrated that RGS2 acted as a regulator of transcription, because it induced the expression of adipogenic markers, such as PPAR $\gamma$ and sterol regulatory element-binding protein-1 [8]. We did not yet study $\mathrm{Gq}$ activation in adipocytes from humans carrying different RGS2 genotypes, but we found that adipocytes from $G G$ homozygous men showed higher PPAR $\gamma$ protein levels than those from men carrying the $C$ allele or women, irrespective of their RGS2 genotype (data not shown). In addition to the metabolic traits of the syndrome, RGS2 might also influence the blood pressure phenotype. Indeed, RGS2-deficient mice develop hypertension [34], mediated via an angiotensin II-dependent increase in vascular tone [34], decreased relaxation in response to vasodilatators [35], and perhaps changes in autonomic nervous function [36].

In keeping with the present experimental and epidemiological findings, Poulsen and coworkers [22] observed among male and female twins divergent genetic influences on the components of the metabolic syndrome. This sexual dimorphism might be conditioned by the activity of sex hormones, differences in lifestyle, exposure to varying environmental factors, and/or epigenetic mechanisms involving genes mapping to the sex chromosomes. In humans, CRSP2, an X-linked Sp1 cofactor (Fig. 1a) escapes X-inactivation and is therefore expressed at a higher level in female than male tissues, including lymphoblastoid cells and hepatocytes [37]. We cotransfected 3T3-L1 adipocytes with CRSP2 (pCIN4FLAG-TRAP170 [38]) combined with RGS2 promoter constructs containing either the $G$ or $G$ allele. In the presence of CRSP2, the activity of the RGS2 promoter

Table 4 Phenotypic differences in components of the metabolic syndrome score between $G G$ homozygotes and $C$ allele carriers by gender

\begin{tabular}{|c|c|c|c|c|}
\hline \multirow[b]{2}{*}{ Phenotype } & \multicolumn{2}{|l|}{ Men $(n=1478)$} & \multicolumn{2}{|l|}{ Women $(n=1602)$} \\
\hline & Phenotypic difference (95\% confidence interval) & $P$ & Phenotypic difference (95\% confidence interval) & $P$ \\
\hline Mean arterial pressure $(\mathrm{mmHg})^{\mathrm{a}}$ & $+0.79(-0.24$ to +1.82$)$ & 0.13 & $-0.42(-1.49$ to +0.66$)$ & 0.45 \\
\hline Body mass index $\left(\mathrm{kg} / \mathrm{m}^{2}\right)^{\mathrm{b}}$ & $+0.34(-0.01$ to +0.70$)$ & 0.06 & $-0.01(-0.44$ to +0.42$)$ & 0.97 \\
\hline Waist-to-hip ratio ${ }^{c}$ & $+0.004(-0.001$ to +0.009$)$ & 0.10 & $-0.001(-0.006$ to +0.005$)$ & 0.95 \\
\hline Serum HDL-cholesterol $(\mathrm{mmol} / \mathrm{l})^{\mathrm{d}}$ & $-0.035(-0.072$ to +0.002$)$ & 0.07 & $-0.032(-0.067$ to +0.003$)$ & 0.07 \\
\hline Serum triglycerides (\%) & $+6.59(+1.02$ to +12.5$)$ & 0.02 & $+0.16(-4.35$ to +4.88$)$ & 0.94 \\
\hline Blood glucose (\%) & $+0.52(-1.44$ to +2.57$)$ & 0.69 & $-1.69(-3.42$ to +0.07$)$ & 0.08 \\
\hline
\end{tabular}

Phenotypic differences were computed by subtracting the value in C allele carriers from that in GG homozygotes. For logarithmically transformed variables (triglycerides and glucose), the phenotypic difference is expressed as a percentage. Statistical parameters, which were obtained by generalized estimating equations [20], were adjusted for country, age (linear and squared terms), smoking and alcohol consumption. Additional adjustments included: for blood pressure, body mass index and use of antihypertensive drugs; for body mass index, use of $\beta$-blockers and diuretics; for triglycerides and high-density lipoprotein (HDL)-cholesterol, body mass index and use of $\beta$-blockers, diuretics and lipid-lowering drugs, and type of alcohol used (beer, wine or liquor); and for blood glucose, body mass index and use of antidiabetic drugs. Analyses in women were additionally adjusted for intake of the contraceptive pill and menopause. ${ }^{\text {a }}$ Mean arterial blood pressure is the diastolic blood pressure plus onethird of the difference between systolic and diastolic blood pressures (average of five readings at the participant's homes). ${ }^{\mathrm{b}}$ The body mass index is weight in kilograms divided by the square of the height in meters. ${ }^{c}$ The waist-to-hip ratio is the smallest circumference at the waist divided by the largest circumference at the hip level.

${ }^{\mathrm{d}}$ To convert values for cholesterol to milligrams per decilitre, divide by 0.02586 . 
was significantly downregulated (data not shown). We speculate that this mechanism might explain why men, having lower CRSP2 levels [37], might experience less RGS2 promoter inhibition, express more RGS2, and hence might be more susceptible to the metabolic syndrome. Obviously, other mechanisms might also be involved, such as genetic variation located to the human $\mathrm{Y}$ chromosome [39,40], interference of RGS2 with the G-protein signalling pathways that control lipolysis or adipocyte differentiation, or interaction of RGS2 with other genes, such as the peroxisome proliferator-activated receptor $\gamma 2$ Pro12Ala [41] and the G-protein $\beta 3$ subunit C825T [4] polymorphisms. Finally, recent research indicates a major role for genetic susceptibility to the metabolic syndrome [42]. Nutrition clearly plays an important role in the development and progression of this condition. The genetic background can interact with habitual dietary fat composition, thereby affecting predisposition to the metabolic syndrome, and may determine an individual's responsiveness to altered dietary fat intake [42].

In conclusion, we discovered a $C$ to $G$ substitution at position -391 of the RGS2 promoter, which in in-vitro and ex-vivo experiments stimulated RGS2 expression and which in epidemiological studies correlated with the metabolic syndrome in men. Further experimental and clinical research should establish whether the RGS2 $-391 C$ to $G$ polymorphism might be a target for preventive or therapeutic intervention in men and to what extent it might play a role in the pathogenesis of the metabolic syndrome in women. The prevalence of syndrome $\mathrm{X}$ is reaching epidemic proportions not only in industrialized countries with a western lifestyle [1], but also in the developing nations of Asia [43]. If confirmed, our observations might therefore have important implications for the prevention and the treatment of the metabolic syndrome.

\section{Acknowledgements}

The authors acknowledge the technical assistance of Sandra Covens, Lieve Gijsbers, Marie-Jeanne Jehoul, Chantal Thys, Sylvia Van Hulle, Tom Richart, and Christine Wittevrongel (University of Leuven, Belgium). Brigitte Egbers (Department of Internal Medicine, Campus Benjamin Franklin, Berlin, Germany) helped in genotyping.

\section{References}

1 Flegal KM, Carroll MD, Ogden CL, Johnson CL. Prevalence and trends in obesity among US adults, 1999-2000. JAMA 2002; 288:17231727.

2 Haffner SM, Valdez RA, Hazuda HP, Mitchell BD, Morales PA, Stern MP. Prospective analysis of the insulin-resistance syndrome (syndrome $\mathrm{X}$ ). Diabetes 1992; 41:715-722.

3 Su HL, Malbon CC, Wang HY. Increased expression of $\mathrm{G}_{\mathrm{i}}$ alpha 2 in mouse embryo stem cells promotes terminal differentiation to adipocytes. Am J Physiol 1993; 265:C1729-C1735.

4 Brand E, Wang JG, Herrmann SM, Staessen JA. An epidemiological study of blood pressure and metabolic phenotypes in relation to the $\mathrm{G} \beta_{3} \mathrm{C} 825 \mathrm{~T}$ polymorphism. J Hypertens 2003; 21:729-737.
5 Hollinger S, Hepler JR. Cellular regulation of RGS proteins: modulators and integrators of G protein signaling. Pharmacol Rev 2002; 54:527-559.

6 Siderovski DP, Heximer SP, Forsdyke DR. A human gene encoding a putative basic helix-loop-helix phosphoprotein whose mRNA increases rapidly in cycloheximide-treated blood mononuclear cells. DNA Cell Biol 1994; 13:125-147.

7 Imagawa M, Tsuchiya T, Nishihara T. Identification of inducible genes at the early stage of adipocyte differentiation of 3T3-L1 cells. Biochem Biophys Res Commun 1999; 254:299-305.

8 Nishizuka M, Honda K, Tsuchiya T, Nishihara T, Imagawa M. RGS2 promotes adipocyte differentiation in the presence of ligand for peroxisome proliferator-activated receptor $\gamma$. J Biol Chem 2001; 276:29625-29627.

9 Tseng CC, Zhang XY. Role of regulator of G protein signaling in desensitization of the glucose-dependent insulinotropic peptide receptor. Endocrinology 1998; 139:4470-4475.

10 Hegele RA, Brunt JH, Connelly PM. Genetic variation on chromosome 1 associated with variation in body fat distribution in men. Circulation 1995; 92:1089-1093.

11 Nakayama T, Soma M, Kanmatsuse K, Kokubun S. The microsatellite alleles on chromosome 1 associated with essential hypertension and blood pressure levels. J Hum Hypertens 2004; 18:823-828.

12 Langefeld CD, Wagenknecht LE, Rotter Jl, Williams AH, Hokanson JE, Saad MF, et al. Linkage of the metabolic syndrome to 1q23-q31 in Hispanic families. The Insulin Resistance Atherosclerosis Study Family Study. Diabetes 2004; 53:1170-1174.

13 Kuznetsova T, Staessen JA, Kawecka-Jaszcz K, Babeanu S, Casiglia E, Filipovsky J, et al. Quality control of the blood pressure phenotype in the European Project on Genes in Hypertension. Blood Press Monit 2002; 7:215-224.

14 Staessen JA, Fagard R, Amery A. Life style as a determinant of blood pressure in the general population. Am J Hypertens 1994; 7:685-694.

15 Expert Panel on the Identification Evaluation and Treatment of Overweight and Obesity in Adults. Clinical guidelines on the identification, evaluation, and treatment of overweight and obesity in adults: executive summary. $\mathrm{Am} \mathrm{J}$ Clin Nutr 1998; 68:899-917.

16 Ding $\mathrm{H}$, Benotmane AM, Suske G, Collen D, Belayew A. Functional interactions between Sp1 or Sp3 and the helicase-like transcription factor mediate basal expression from the human plasminogen activator inhibitor-1 gene. J Biol Chem 1999; 274:19573-19580.

17 MacDougald OA, Cornelius P, Liu R, Lane MD. Insulin regulates transcription of the CCAAT/Enhancer Binding Protein (C/EBP) $\alpha, \beta$, and $\delta$ genes in fully-differentiated 3T3-L1 adipocytes. J Biol Chem 1995; 270:647-654.

18 Thiel G, Schoch S, Petersohn D. Regulation of synapsin I gene expression by the zinc finger transcription factor zif268/egr-1. J Biol Chem 1994; 269:15294-15301.

19 Freson K, Hashimoto H, Thys C, Wittevrongel C, Danloy S, Morita Y, et al. The pituitary adenylate cyclase-activating polypeptide is a physiological inhibitor of platelet activation. J Clin Invest 2004; 113:905-912.

20 Trégouët DA, Ducimetière $P$, Tiret $L$. Testing associations between candidate-gene markers and phenotype in related individuals by use of estimating equations. Am J Hum Genet 1997; 61:189-199.

21 Matthews DR, Hosker JP, Rudenski AS, Naylor BA, Treacher DF, Turner RC. Homeostasis model assessment: insulin resistance and $\beta$-cell function from fasting glucose and insulin concentrations in man. Diabetologia 1985; 28:412-419.

22 Poulsen P, Vaag A, Kyvik K, Beck-Nielsen H. Genetic versus environmental aetiology of the metabolic syndrome among male and female twins. Diabetologia 2001; 44:537-543.

23 Kleinbaum DG, Kupper LL, Muller KE. Variable reduction and factor analysis. In: Applied regression analysis and other multivariate methods. 2nd edition. Boston, MA: PWS-Kent Publishing Company; 1988. 595642.

24 Abecasis GR, Cardon LR, Cookson WOC. A general test of association for quantitative traits in nuclear families. Am J Hum Genet 2000; 66:279-292.

25 Werner T. Computer-assisted analysis of transcription control regions Matinspector and other programs. Methods Mol Biol 2000; 132:337349.

26 Tang QQ, Jiang MS, Lane MD. Repressive effect of Sp1 on the C/EBP alpha gene promoter: role in adipocyte differentiation. Mol Cell Biol 1999; 19:4855-4865.

27 Weiss R, Dziura J, Burgert TS, Tamborlane WV, Taksali SE, Yeckel CW, et al. Obesity and the metabolic syndrome in children and adolescents. N Engl J Med 2004; 350:2362-2374.

28 Mitchell BD, Kammerer CM, Mahaney MC, Blangero J, Comuzzie AG, Atwood LD, et al. Pleiotropic effects of genes influencing insulin levels on lipoprotein and obesity measures. Arterioscler Thromb Vasc Biol 1996; 16:281-288. 
Hong Y, Pedersen NL, Brismar K, de Faire U. Genetic and environmental architecture of the features of the insulin-resistance syndrome. Am J Hum Genet 1997; 60:143-152.

30 Heximer SP, Watson N, Linder ME, Blumer KJ, Hepler JR. RGS2/G0S8 is a selective inhibitor of Gq $\alpha$ function. Proc Natl Acad Sci U S A 1997; 94:14389-14393.

31 Burchett SA. In through the out door: nuclear localization of the regulators of G protein signaling. J Neurochem 2003; 87:551-559.

32 Song L, Zmijewski JW, Jope RS. RGS2: regulation of expression and nuclear localization. Biochem Biophys Res Comm 2001; 283:102-106.

33 Imamura T, Vollenweider P, Egawa K, Clodi M, Ishibashi K, Nakashima N, et al. $\mathrm{G}$ alpha-q/11 protein plays a key role in insulin-induced glucose transport in 3T3-L1 adipocytes. Mol Cell Biol 1999; 19:6765-6774.

34 Heximer SP, Knutsen RH, Sun X, Kaltenbronn KM, Rhee MH, Peng N, et al. Hypertension and prolonged vasoconstrictor signaling in RGS2-deficient mice. J Clin Invest 2003; 111:445-452.

35 Tang M, Wang G, Lu P, Karas RH, Aronovitz M, Heximer SP, et al. Regulator of G-protein signaling-2 mediates vascular smooth muscle relaxation and blood pressure. Nat Med 2003; 9:1506-1512.

36 Oliveira-dos-Santos A, Matsumoto G, Snow BE, Bai D, Houston FP, Whishaw IQ, et al. Regulation of $\mathrm{T}$ cell activation, anxiety, and male aggression by RGS2. Proc Natl Acad Sci U S A 2000; 97:12272-12277.

37 Yoshikawa H, Fujiyama A, Nakai K, Inazawa J, Matsubara K. Detection and isolation of a novel human gene located on Xp112-p114 that escapes X-inactivation. Genomics 1998; 1998:237-246.

38 Gu W, Malik S, Ito M, Yuan CX, Fondell JD, Zhang X, et al. A novel human SRB/MED-containing cofactor complex, SMCC, involved in transcription regulation. Mol Cell 1999; 3:97-108.

39 Charchar FJ, Tomaszewski M, Padmanabhan S, Lacka B, Upton MN, Inglis GC, et al. The $\mathrm{Y}$ chromosome effect on blood pressure in two European populations. Hypertension 2002; 39:353-356.

40 Charchar FJ, Tomaszewski M, Lacka B, Zakrzewski J, ZukowskaSzczechowska E, Grzeszczak W, Dominiczak AF. Association of the human $Y$ chromosome with cholesterol levels in the general population. Arterioscler Thromb Vasc Biol 2004; 24:308-312.

41 Brand-Herrmann SM, Kuznetsova T, Weichert A, Stolarz K, Tikhonoff V, Schmidt-Petersen $\mathrm{K}$, et al. Alcohol intake modulates the genetic association between HDL cholesterol and the PPAR- $\gamma 2$ Pro12Ala polymorphism. J Lipid Res 2005; 46:913-919.

42 Phillips C, Lopez-Miranda J, Perez-Jiminez F, McManus R, Roche HM. Genetic and nutrient determinants of the metabolic syndrome. Curr Opin Cardiol 2006; 21:185-193.

43 Cooperation Group: Further Study of Risk Factors for Stroke and Coronary Heart Disease. The prevalence of the metabolic syndrome in a 11 provinces cohort in China. Chin J Prev Med 2002; 36:298-300.

\section{Appendix}

The following investigators participated in the EPOGH Study: Belgium (Leuven) - E. Balkestein, H. Celis, E. Den Hond, R. Fagard, J. Gąsowski, T. Kuznetsova, Y. Li, T. Nawrot, M. Plusquin, L. Thijs, J.A. Staessen, and J.G. Wang; Bulgaria (Sofia) - C. Nachev, A. Postadjian, E. Prokopova, E. Shipkovenska, and K. Vitljanova; $C_{\text {zech }}$ Republic (Pilsen and Prague) - O. Beran, J. Filipovský, L. Golán, T. Grus, G. Grusová, M. Jachymová, J. Kucerova, Z. Marecková, J. Peleška, V. Svobodova, and M. Tichá; Italy (Padua) - E. Casiglia, A. Pizziol, and V. Tikhonoff; Poland (Cracow) - A. Adamkiewicz-Piejko, M. Cwynar, T. Grodzicki, K. Kawecka-Jaszcz, W. Lubaszewski, A. Olszanecka, K. Stolarz, B. Wizner, W. Wojciechowska, and J. Zyczkowska; Romania (Bucharest) - S. Babeanu, D. Jianu, C. Sandu, D. State, and M. Udrea; Russian Federation (Novosibirsk) - T. Kuznetsova, S. Malyutina, Y. Nikitin, E. Pello, M. Ryabikov, and M. Voevoda. Project Coordinator - J.A. Staessen; Scientific Coordinator - K. Kawecka-Jaszcz; Steering Committee - S. Babeanu, E. Casiglia, J. Filipovský, K. Kawecka-Jaszcz, C. Nachev, Y. Nikitin, J. Peleška, and J.A. Staessen; Data Management Committee - T. Kuznetsova, Y. Li, J.A. Staessen, K.
Stolarz, V. Tikhonoff, and J.G. Wang; Advisory Committee on Molecular Biology - G. Bianchi (Universitá Vita Salute, Milan, Italy), E. Brand, S.M. Brand-Herrmann, P. Schiffers [Cardiovascular Research Institute Maastricht (CARIM), Maastricht, The Netherlands], and H.A. Struijker-Boudier (CARIM). 